\title{
Effects of Social Deviance Labels on Judgements of Facial Attractiveness: A Comparison of Labelling Procedures Using Japanese Raters
}

\author{
Rotem Kowner \\ The Hebrew University, Jerusalem, Israel
}

\begin{abstract}
Are people labelled as social deviants also perceived as less physically attractive? Four studies conducted in Japan examined judgements of male social-deviants' attractiveness using several labelling procedures. Study 1 determined attractiveness judgement and social distance of various social groups, and Study 2 examined the effect of three labels on attractiveness judgement of 16 portraits. In Studies 3 and 4 subjects were asked to match 8 or an unlimited number of the 16 portraits with the same 3 labels. Findings indicate that labelling a person negatively resulted in a decrease in attractiveness ratings. Overall, however, the labelling pattern was found to affect attractiveness judgement. Finally, this study provides cross-cultural support for the stereotypical association between social deviants and low attractiveness.
\end{abstract}

Est-ce que les gens étiquetés comme socialement deviants, sont aussi perçus comme moins beaux? Quatre études conduites au Japon examinent les jugements portés sur la beauté des hommes socialement deviants, en utilisant plusieurs procédés d'etiquetage. L'étude 1 determine le jugement de beaute et la distance sociale de differents groupes sociaux; l'étude 2 examine l'effet de 3 étiquetages sur le jugement de beauté porté sur 16 portraits. Dans les études 3 et 4 on a demandé aux participants de faire correspondre huit ou un nombre illimité des 16 portraits. Les résultats indiquent que le type (négative) et le modèle d'étiquetage affectent le jugement de beauté. Finalement, cette étude donne un appui interculturel pour l'association stéréotypique entre les personnes socialement déviantes et laideur.

We see the world the way we do not because that is the way it is but because we have these ways of seeing.

Ludwig Wittgenstein (1958)

One of the recurrent themes in social psychology has been the extent to which social reality is constructed by the participants involved in interpersonal interaction (e.g. Fiske \& Neuberg, 1990; Jussim, 1991). It has been often demonstrated that people tend to construct not only their social reality but even the image of the people around them. Numerous studies on processes of impression formation have shown how social beliefs, physical features, expectations, labels, and other information about people are integrated to form judgements of them on various dimensions. Nevertheless, it is still debatable how accurate such perceptions and beliefs are and how much influence they exert on the construction of social reality.

The discourse regarding the relations between social labels, physical appearance, and a person's "true" character seems to have especially long roots. In one of the milestones of modern criminology, the book The criminal man, Cesare

Requests for reprints should be addressed to Rotem Kowner, Department of General Studies, Haifa University, Haifa 31905, Israel.

I thank Sosuke Miyamoto for his collaboration in conducting the first two surveys, Toshiki Ogawa, Mariko Yamamoto, Roy Ron, Mukund Subramanian, Jennifer Heller, and several anonymous reviewers for their helpful comments on earlier drafts, and Haruhiko Shobo from Meikai University, Takeshi Miyamoto from Utsunomiya University, Takafumi Terasawa and $\mathrm{T}$. Ishii from the University of Tsukuba, and $\mathrm{K}$. Hasebe from the University of Library and Information for their assistance in conducting the empirical part of this study. 
Lombroso (1887) asserted that criminals are a product of heredity, and can be recognized through specific anatomical signs (stigmata) to be seen on the face. Lombroso, albeit his seemingly novel and "scientific" approach, was not the herald of modern social psychology. He followed, in fact, a long tradition of a pseudoscience called physiognomy, which dates to classical Greece.

Founded by Aristotle, physiognomy was the earliest attempt to judge character and disposition by observing facial features. A few decades earlier, Plato had established in Greater Hippias a dual link between beauty and goodness which would have a lasting effect on physiognomy (Plato, 1963). Plato, in fact, meant moral rather than physical beauty, but the association spread to other fields, and eventually facial beauty became one of the major elements in physiognomy. Consequently, the basic assumption of "modern" physiognomy, which emerged during the Enlightenment, was that facial appearance corresponds to mental reality, and that facial beauty represents goodness and truth (Graham, 1993; Rivers, 1994).

Although theories linking facial features and character lacked empirical rigour and received very little scientific support, they all attracted legions of followers (Alley, 1988; Brandt, 1980). In fact, regardless of people's knowledge of physiognomy, all humans are amateur "physiognomists", since they seek to rely on the rich information they obtain from others' faces when making inferences about their character and personality (Berry \& McArthur, 1986; McArthur, 1982). Hence, it is not surprising, perhaps, that physiognomic beliefs have persisted till today (Hatfield \& Sprecher, 1986; but see also Eagly, Ashmore, Makhijani, \& Longo, 1991; Feingold, 1992). They are manifested, for example, in the association people tend to make between high attractiveness and positive stereotypes on one hand (Berscheid \& Walster, 1974; Dion, Berscheid, \& Walster, 1972), and low attractiveness and social deviancy on the other.

\section{Deviancy and Stereotypes of Physical Attractiveness}

From a social and psychological point of view, the stereotypical association between social deviants and low attractiveness is of greater importance due to the detrimental implications it has on those who are labelled as social deviants as well as on those who are perceived as unattractive. Whether "deviant" people are perceived as unattractive or unattractive people are labelled as deviants, both are suffering from labelling effects, which is a phenomena whereby a perceivers' evaluation and judgement of different targets is dependent on the groups to which individual targets belong (Jussim, Nelson, Manis, \& Soffin, 1995). Applying a label to a target person, as studies on various aspects of human interaction show, often influences how perceivers judge and evaluate that target's behaviour and features (e.g. Kowner, 1996).

In the same fashion, labelling also influences the way perceivers judge a target person's appearance (e.g. Innala \& Ernulf, 1994; Shepherd, Ellis, McMurran, \& Davies, 1978). This effect also occurs in the opposite direction, that is, less attractive individuals are more likely to be selected as having symptoms of mental disorder (Jones, Hannson, \& Phillips, 1978) or epilepsy (Hannson \& Duffield, 1976), and even clinicians tend to attribute unattractive patients with less favourable prognoses than attractive patients (Barocas \& Vance, 1974).

From personal and shared social experience, the individual perceiver derives a set of person "types" that are presented in the form of abstract images or interrelated features. In her model of impression formation, Brewer (1988) argued that person categories are usually pictoliteral representations, and compared to nonvisual concepts, are more specific, configural, and unmediated by verbal descriptions (see also Klatzky, 1984). Research on social stereotypes indicates that stereotypes have a visual component and that labels associated with certain people (women, lawyers, etc.) can elicit rich visual images of the kind of person represented by the label (Deaux \& Lewis, 1984; Klatzky, Martin, \& Kane, 1982). Further, these studies suggest that individuals maintain visual "templates" that correspond to memorable social experiences, and that verbal labels elicit visual characteristics and visual information generates trait inferences.

Images of deviancy are a special case of general cognitive tools called categories, which people use to describe and sort the world. If we define social deviancy as a departure of certain types of behaviour from the norms of a particular society or group at a particular time (Clinard, 1968; Dinitz, Dynes, \& Clark, 1969), a wide variety of labels may be included under this definition. Yet, are all of them associated with low attractiveness? Not necessarily. 
The relations between physical appearance and the two labels, feminist and homosexual, have been given particular attention. The first studies on the association between attractiveness and feminist attitudes (advocacy of women's rights) pointed out a tendency to associate low attractiveness with support for feminist causes (Goldberg, Gottesdiener, \& Abramson, 1975; Jacobson \& Koch, 1978). However, several researchers who did not find such difference argued that social attitudes toward feminism had been shifting and that it had become an acceptable value (Johnson, Doiron, Brooks, \& Dickinson, 1978; Johnson, Holborn, \& Turcotte, 1979). This argument was supported by Unger, Hilderbrand, and Madar (1982), who found feminism to be associated with unattractive males but not with unattractive females.

Similar evolution has been considered to occur in the social perceptions of homosexuals. Gurwitz and Marcus (1978) found that homosexuals were stereotyped as less attractive than heterosexual, whereas Unger et al. (1982) pointed out that the stereotypes vary according to gender differences. That is, lesbians were found to be associated with low attractiveness whereas homosexual men were not. Conrad and Schneider (1980) suggested that the attitude toward homosexuals reflects a general shift in the United States from a moral-immoral vocabulary to a healthy-sick vocabulary in describing deviance.

\section{Could the Labelling Pattern Affect Attractiveness Judgement?}

Several reasons may account for the inconsistent effect of labels of deviancy upon judgements of attractiveness. One possibility is that the samples of raters (and target persons) in the studies mentioned earlier differed substantially from each other in their attitudes toward social deviants. Alternatively, a number of researchers have suggested that the changing attitudes were a result of a period effect; namely, a recent increase in social awareness and consequently in liberal attitudes toward social deviancy in the USA (e.g. Innala $\&$ Ernulf, 1994). Although these two accounts are plausible, another explanation may underlie the research methodology used by researchers in the field.

A close examination of the various studies on this topic suggests that only few of them used similar measures or procedures. This observation matches a general pattern of research. Namely, social psychologists have concentrated on processes of impression formation, while not examining the manner in which labelling is applied sufficiently. Because judgement of attractiveness is based on perception, I sought initially to distinguish between two types of labelling.

1. Abstract labelling-A categorizing process people conduct on an imagery target. Abstract labelling only concerns targets that cannot be sensed (e.g. visually, audibly, tactually) during the process of labelling. When this type of labelling is used in experimental procedure, it denotes that subjects are instructed to imagine target persons (members of a deviant group) and to rate them on various measures.

2. Concrete labelling-A categorizing process people conduct on a concrete target-person. Concrete labelling concerns targets that can be sensed to a various extent (e.g. observing them in real life or pictures, hearing their voice) during the process of labelling. When this type of labelling is used in experimental procedure, it denotes that subjects are instructed to rate target persons (members of a deviant group) with whom they have physical contact, or at least a concrete representation of that person (e.g. photographs, video).

There are several important differences between abstract labelling and concrete labelling. People conducting abstract labelling are focused on the label rather than on personal features. Because they deal with a schema of a particular group and only few competing representations can disrupt their response, they tend to assess the features in question in extreme terms. When conducting concrete labelling, however, people are exposed to perceptual images of individuals rather than unidividuate images of a whole group. Consequently, several competing features of the targets (e.g. age, hair style, perceived emotion, and mainly "personality") may interfere with their assessment (Stangor \& Lange, 1994). Thus, when conducting abstract labelling people evaluate a trait whereas in concrete labelling people judge a trait, which amounts to more than a semantic difference.

Concrete labelling can further be differentiated according to the source of the label.

1. Imposed labelling - The identification of a social object is conducted by an external source and transmitted in various ways to the person who makes the judgement. When this type of 
labelling is used in experimental procedure, it denotes that target people are depicted as socially deviant, and raters who are aware of the deviancy are requested to rate the targets' physical attractiveness (e.g. Innala \& Ernulf, 1994; Shepherd et al. 1978).

2. Self-generated labelling-The identification of a social object is conducted by the person who makes the judgement. When this type of labelling is used in experimental procedure, it denotes that raters are presented with target people, whose attractiveness was evaluated beforehand. They are told that one or more member of the group is socially deviant and asked to match targets with the pertinent label (e.g. Hansson \& Duffield, 1976; Jones et al., 1978).

There are several important differences between imposed labelling and self-generated labelling. First, the stereotyping mode used in imposed labelling and self-generated labelling differs substantially. In the former labelling pattern, the attractiveness evaluation is based on the inference that "what is good is beautiful", which means that the (negative) label affects the attractiveness judgement. In contrast, the latter pattern is based on the inference "what is beautiful is good", which means that the (low) attractiveness judgement of a target determines its label. Second, labels used in imposed labelling are definite whereas labels used in self-generated labelling are speculative. In other words, people who have limited information about others cannot discard or ignore labels about them, even if these labels are imposed by others. In the case of selfgenerated labelling, however, it is based on speculation and thus as long as one cannot confirm the labels, their impact remains limited.

A third difference between the two patterns is concerned with the awareness of the task. In imposed labelling, the attractiveness evaluation is overt, whereas in the self-generated labelling it is covert. People's awareness of the task may have implications on their responses because, as Dovidio, Evans, and Tyler (1986) observed, when subjects view social-group primes for several seconds and are asked to respond in a stereotypical fashion, they tend to modify their response criteria according to their assumptions about the researchers' hypothesis or what they perceive as socially adequate, but not necessarily according to what they "really" think or feel.

The fourth difference concerns social desirability. Imposed labelling involves social desir- ability, which in turn may affect evaluation of certain labels, whereas self-generated labelling does not, as the prejudicial aspects are covert. Hence, imposed labelling affects attractiveness judgement of targets labelled as deviants whom judges believe to have little social desirability, either as a result of a conformity to social consensus or a personally felt negative affect. This impact of social desirability occurs because the demand for attractive judgement is overt and judges are aware of both the task and the prejudicial attitudes they expose. In contrast, selfgenerated labelling affects attractiveness judgement of targets labelled as deviants whom judges believe to be physically different from nonlabelled "normal" targets. This is because subjects are not aware they are conducting attractiveness judgement and thus they are more likely to reveal their genuine attitudes toward the targets.

\section{The Cultural Factor: The Setting of the Labels in Question}

Jussim et al. (1995) argued that the extent to which people like or dislike different groups provides a more complete understanding of how group labels influence person perception. In the present study, this proposition is of particular importance because it was conducted in a place where cultural dictums and social affection may differ from North America, where most of the research on this topic has been conducted (cf. Markus \& Kitayama, 1991; Weisz, Rothbaum, \& Blackburn, 1984). I was particularly interested in three labels: "homosexual" (doseiaisha), "mental patient" (seishinbyo to shindan sareta jinbutsu [lit. person diagnosed as mentally ill]) and "artist" (geijutsuka), because they are clearly defined in Japan and thus can easily be compared with each other.

Japanese homosexuality has an intricate history. During the Tokugawa era (1603-1867) it was often considered as "a passion more noble and more gracious than heterosexuality". It was encouraged, especially within the samurai class, whereas the love of women was often devalued for its so-called "feminizing effect" (Watanabe \& Iwata, 1989, p. 11). The rapid acquisition of Western values and morals, however, gradually eradicated this tradition, and "an anti-homosexual society has been established" (Watanabe \& Iwata, 1989 , p. 11). Whereas the negative implications of labelling a person as a homosexual are rather 
modern ones, mental illness has had negative connotations in Japan since early history. Nevertheless, the recent history of mental illness in Japan has witnessed an opposite course to that of homosexuality.

Having a family member suffering from a mental disorder had been traditionally considered a great strain on one's family lineage and remained so until recently. Due to the scarcity of mental institutions, the burden of caring for mental patients was placed on the family. Hidden from curious neighbours, people suffering from mental disorder were often left alone in a cold dark room or in a barn. Although negative attitudes toward mental illness have lessened considerably today, medical practitioners may still give schizophrenic patients a disguised diagnosis or "neurasthenia" to protect them from social prejudice associated with mental illness (Munakata, 1989). Moreover, being labelled as mentally ill may still affect the prospect of marriage for other family members, because it is perceived as a characteristic which is transferred in the blood (Hayashida, 1976). The third label, "artist", was chosen because of the positive and somewhat deviant connotations it seems to have in mainstream society.

\section{The Present Study}

The main purpose of the present study was to investigate the extent to which various labelling patterns, defined for the first time in the study, have differing effects on attractiveness judgement of people labelled as social deviants. The fact that the study was conducted in Japan led to a crosscultural subgoal, that is, to examine the existence of labelling effect of deviancy on attractiveness judgement in a non-Western culture. Consequently, three hypotheses were examined:

1. Abstract labelling results in more polarized attractiveness evaluation than concrete labelling. That is, abstract labelling results in lower attractiveness evaluation of groups considered as socially deviant, and higher attractiveness evaluation of groups considered as non-deviant.

2. Self-generated and imposed labelling result in different attractiveness judgements depending on the perception of each label within a specific culture or group of subjects examined.

3. The Japanese attitudes toward deviants resemble the negative attitudes found earlier in other Western countries. This is due to a universal effect of categorization, which links negative stereotypes regarding deviancy with attitudes and perceptions.

\section{STUDY 1}

\section{Effect of Abstract Labelling on Attractiveness Judgement}

\section{Overview}

The first study sought to identify social perceptions in Japan toward several groups of presumed deviant and non-deviant people, using measures of social acceptance and evaluation of physical attractiveness. This study employed abstract labelling, by asking subjects to imagine typical persons in each label and to rate their attractiveness as well as a subjects' willingness to accept them as friends.

\section{Method}

Subjects and Design. The subjects were 160 undergraduates ( 80 males and 80 females; mean age $\pm S D=21.0 \pm 2.8$ years) enrolled in the University of Tsukuba. All were native Japanese who participated at the request of their instructors. The design consisted of two dependent variables: ratings of attractiveness and social acceptance, and one repeated measure within-subjects independent variable called group.

Testing Material. Two questionnaires were used in this study. The first, the Physical Attractiveness Questionnaire, lists nine groups of men with various labels, to be rated for attractiveness on a scale ranging from 1 (very unattractive) to 7 (very attractive). Four of the nine groups were presumed to carry a positive label connotation ("physicians", "academics", "artists", "white collar employees"), four groups were presumed to carry a negative label connotation ("exconvicts", "mental patients", "homosexuals", "obese"), and the subjects" own group ("students") was a baseline, which could be considered from the viewpoint of the subjects as a nolabel condition. The second questionnaire, the Social Acceptance Questionnaire, is comprised of the same list of nine groups used in the first questionnaire. Subjects are requested to imagine a person from each group and to indicate their willingness to accept that person as a friend. Ratings range from 1 (absolutely unwilling to accept) to 7 
(absolutely willing to accept). The groups were listed in various orders to avoid interference of group position.

Procedure. The survey was conducted in a classroom and presented as "A survey on group image". Subjects randomly received either the Physical Attractiveness Questionnaire or the Social Acceptance Questionnaire, and were asked to imagine male members of each of the nine groups and to rate their attractiveness or willingness to accept them as friends.

\section{Results}

To determine whether the label of the groups rated and the sex of the raters affected the attractiveness evaluations of the nine groups, a repeated measure analysis of variance (ANOVA) was conducted on the attractiveness scores of the nine groups using group and subjects' sex as independent variables. There was a main effect of group, $F(8,624)=39.1, P<.0001$, and an interaction between group and sex, $F(8,624)=$ $2.5, P<.01$. Artists $(M=4.84)$ were rated as the most attractive, students $(M=4.50)$, who served as a baseline group, were rated third, and obese persons $(M=2.66)$ were rated as the least attractive. A similar ANOVA conducted on the social acceptance scores of the nine groups yielded main effects of group and sex, $F(8,624)=$ 64.2, $P<.0001 ; F(1,624)=5.8, P<.02$, respectively, and an interaction between group and sex, $F(8,624)=5.0, P<.0001$. Students were rated as the most desirable group $(M=$
6.34), whereas mental patients were rated as the least desirable $(M=3.40)$. Women's ratings ( $M=4.86)$ of social acceptance toward the nine groups were higher than men's ratings $(M=$ 4.53) (Table 1).

Subsequently, repeated measure ANOVAs were conducted on the three groups ("artist," "homosexual," "mental patient") in each questionnaire. Artists were rated the highest ( $M=$ 4.84), whereas mental patients $(M=3.04)$ and homosexuals $(M=2.90)$ were rated almost the same and much lower, $F(2,156)=48.5, P<$ .0001 . A similar analysis of the social acceptance ratings revealed that artists were the most desirable $(M=4.95)$, whereas homosexuals $(M=3.55)$ and mental patients $(M=3.40)$ were rated almost the same and much lower, $F(2,156)=40.1, P<$ .0001 . In addition, there was a main effect of sex: women $(M=4.39)$ expressed more acceptance toward the three groups than did men $(M=$ 3.54), $F(1,78)=14.7, P<.0002$. The analysis also revealed an interaction between group and sex, especially in regard to homosexuals and mental patients. A repeated-measure ANOVA on these two labels indicated that women expressed greater acceptance for homosexuals $(M=4.43)$ than for mental patients $(M=3.55)$, whereas men rated mental patients $(M=3.25)$ as more desirable than homosexuals $(M=2.68), F(1,78)=$ 13.1, $P<.0005$. Women also rated both labels higher than males, $F(1,78)=16.3, P<.0001$ (Table 1).

Finally, we examined sex differences in the rank order of the average ratings for the nine labels. Spearman rank coefficient for the ratings

TABLE 1

Attractiveness and Social Acceptance Scores for Nine Labels (the Indicators of Significance Refer to Sex Difference)

\begin{tabular}{|c|c|c|c|c|c|c|}
\hline \multirow[b]{2}{*}{ Label Group } & \multicolumn{3}{|c|}{ Attractiveness Judgement } & \multicolumn{3}{|c|}{ Social Acceptance } \\
\hline & $\begin{array}{c}\text { Total } \\
(N=80) \\
M \quad(S D)\end{array}$ & $\begin{array}{c}\text { Men } \\
(N=40) \\
M \quad(S D)\end{array}$ & $\begin{array}{c}\text { Women } \\
(N=40) \\
M \quad(S D)\end{array}$ & $\begin{array}{c}\text { Total } \\
(N=80) \\
M \quad(S D)\end{array}$ & $\begin{array}{c}\text { Men } \\
(N=40) \\
M \quad(S D)\end{array}$ & $\begin{array}{c}\text { Women } \\
(N=40) \\
M \quad(S D)\end{array}$ \\
\hline Artists & $4.84(1.35)$ & $4.70(1.57)$ & $4.96(1.10)$ & $4.95(1.31)$ & $4.70(1.32)$ & $5.20(1.27)^{*}$ \\
\hline Homosexuals & $2.90(1.62)$ & $2.63(1.68)$ & $3.18(1.53)$ & $3.55(1.79)$ & $2.68(1.54)$ & $4.43(1.58)^{* * *}$ \\
\hline Mental patients & $3.04(1.38)$ & $3.10(1.55)$ & $2.98(1.21)$ & $3.40(1.32)$ & $3.25(1.32)$ & $3.55(1.32)$ \\
\hline Students & $4.50(0.99)$ & $4.42(1.13)$ & $4.56(0.84)$ & $6.34(0.84)$ & $6.28(0.91)$ & $6.40(0.78)$ \\
\hline Ex-convicts & $2.93(1.41)$ & $3.25(1.37)$ & $2.60(1.39)^{* *}$ & $3.46(1.30)$ & $3.40(1.32)$ & $3.53(1.30)$ \\
\hline Academics & $4.39(1.36)$ & $4.53(1.36)$ & $4.25(1.35)$ & $4.93(1.10)$ & $4.95(1.24)$ & $4.90(0.96)$ \\
\hline Obese persons & $2.66(1.25)$ & $2.95(1.34)$ & $2.38(1.10)^{* *}$ & $5.08(1.36)$ & $5.15(1.33)$ & $5.00(1.40)$ \\
\hline Physicians & $4.59(1.23)$ & $4.78(1.27)$ & $4.40(1.17)$ & $5.20(1.06)$ & $5.13(1.04)$ & $5.28(1.09)$ \\
\hline $\begin{array}{l}\text { White collar } \\
\text { employees }\end{array}$ & $3.96(1.11)$ & $3.73(0.96)$ & $4.20(1.20)^{*}$ & $5.34(1.02)$ & $5.23(0.95)$ & $5.45(1.09)$ \\
\hline
\end{tabular}


made by men and women indicated that there was significant agreement between subjects of both sexes regarding most of the labels, either for attractiveness ( $R h o=.80,9$ items) or social acceptance ( $R h o=.90,9$ items).

\section{Discussion}

The findings confirmed the initial predictions concerning the negative connotation of the "homosexual" and the "mental patient" labels, and the positive connotation of the "artist" label regarding physical attractiveness evaluation and social acceptance. The findings also revealed a sex difference concerning the social acceptance of homosexual and mental-patient men. Although, in general, there was high agreement among men and women raters regarding most of the labels, they differed in their social acceptance scores for homosexuals and to a lesser extent for mental patients. Our male subjects expressed marked repulsion toward homosexuals by rating them as the least attractive and as the least socially desirable group. Thus, our sample of 80 Japanese male students revealed the presence of strong homophobia, which is classically defined as the dread of being in close quarters with homosexuals (cf. Weinberg, 1972). Earlier studies found that homophobic individuals tend to attribute more negative traits to homosexual men than to heterosexuals. They also indicate that men, notably Western men, express greater homophobia than women (e.g. Steffensmeier \& Steffensmeier, 1974). It is clear, in our case, that the fear of contact with homosexuals, rather than close familiarity with them, is the cause of the low attractiveness ratings for people abstractly labelled as homosexuals.

\section{STUDY 2}

\section{Effect of Imposed Labelling on Attractiveness Judgement}

\section{Overview}

The findings of the first study point out the existence of notable differences in ratings of physical attractiveness of artists and students (who served as a baseline group) on one hand, and the homosexuals and mental patients on the other. Nevertheless, it was hypothesized that once raters face real targets, or even their photographs (concrete labelling), under the same labels, the difference would greatly diminish. Hence, the purpose of this study was to examine the effect of imposed labelling (using the same groups as in Study 1) on physical attractiveness judgement of photographs of 16 males.

\section{Method}

Subjects and Design. The subjects were 308 undergraduates (184 males and 124 females; mean age $\pm S D=19.6 \pm 1.2$ years) enrolled in either Utsunomiya University, Utsunomiya, or the University of Information and Library, Tsukuba, both in the vicinity of Tokyo. All were native Japanese who participated at the request of their instructors. Scores of 11 subjects who either did not understand the instructions or did not fully cooperate were deleted. The design consisted of two between-subjects factors: group ("homosexual", "mental patient", and "artist") and subjects' sex, and one within-subjects factor: labelling (scores of labelled target persons vs. scores of persons not labelled).

\section{Testing Material.}

1. Stimuli-Sixteen portraits of Japanese normal male adults with unknown sexual orientation were used (mean age $=32.9$; range $=19-50$ years). They were photographed with a $35 \mathrm{~mm}$ camera at a fixed distance, and were instructed to look directly at the lens of the camera, and to present a neutral expression. The 16 pictures were selected from a large pool to represent a wide range of attractiveness. During the preparation of the portraits all background details and clothes were erased from the monochrome pictures to avoid indication of status or other irrelevant information. The resulting portraits were presented in a form of a booklet with a single $25 \times 18 \mathrm{~cm}$ on each page. The pictures were divided to two clusters, each comprised of eight pictures of a similar age and attractiveness range.

2. Questionnaires-The dependent measure of this study was the ratings of facial attractiveness of the stimuli. Each stimulus person was evaluated on a 10 -point Likert scale ranging from very unattractive (1) to very attractive (10). This measure and the two clusters of pictures were arranged in booklets. Each booklet contained explanations regarding the purpose of the study, and one of the two eight-picture clusters arranged in a random order (the physical attractiveness measure was attached in the bottom of each picture). The second part included further expla- 
nation about one of the three groups used in the study, followed by the remaining eight pictures.

Procedure. The study was conducted in a class setting and was presented as "Research on the relation between the face and genetic constitution". Each subject randomly received an envelope containing the questionnaire and the picture booklet. The first part of each booklet was identical, and the subjects were simply asked to rate the eight pictures ("the no-label cluster") as "a part of facial recognition research." After a short break, the subjects were told that the following eight pictures ("the labelled cluster") as a whole were either of homosexuals, mental patients, or artists. At this stage, the subjects were provided with an explanation regarding the experiment in order to induce their cooperation. It stated that there had been growing evidence for a link between the human face and one's genetic constitution, and that the present research aimed to examine that link. Upon completion, the subjects were debriefed about the manipulation and the goals of the study.

\section{Results}

A preliminary analysis of the average attractiveness score of the two eight-picture clusters indicated that they did not differ from each other in the no-label condition. Subsequently, the effect of the group on the attractiveness ratings were analysed. A 3 (group) $\times 2($ sex $)$ repeated measure ANOVA on the ratings with and without labels revealed main effects of group and labelling, $F(2,288)=3.4, P<.04 ; F(1,288)=4.0, P<$ .05 , respectively, as well as an interaction between group and labelling, $\mathrm{F}(2,288)=9.6, P$ $<.0001$. Artists, again, were rated as the most attractive $(M=4.56)$, whereas mental patients $(M=4.10)$ and homosexuals $(M=3.89)$ were rated as the least attractive. Analysis within each group revealed a main effect of labelling only within the homosexual group. Targets labelled as homosexual $(M=3.89)$ were rated as less attractive than when not so labelled $(M=$ 4.32), $F(1,102)=27.7, P<.0001$ (Table 2).

\section{Discussion}

The findings show that negative labels may decrease attractiveness ratings of unfamiliar people under various labels (in this case, there was a clear effect for the label of homosexuals but not for mental patients), whereas positive labels may somewhat increase their ratings. Compared with abstract labelling, the findings also demonstrate that the effect of concrete labelling on attractiveness judgements is much weaker. It appears that the differences between the ratings for people labelled with positive (or baseline labels) and negative labels are about $0.5 S D$, as compared with 1-2 $S D$ in the abstract labelling condition examined in Study 1.

Interestingly, the sex difference we found in Study 1 regarding the attractiveness ratings of homosexual men was not revealed in this study. The lack of sex difference suggests that homophobia, which affected attractiveness ratings of men labelled as homosexual in the abstract label condition, has little effect, if any, on the ratings of men labelled as homosexual when they can be observed (concrete label).

\section{STUDY 3}

\section{Effect of Self-generated Labelling on Attractiveness Judgement (1)}

\section{Overview}

The third study examined the effect of selfgenerated labelling on attractiveness ratings of

TABLE 2

Attractiveness Score for Labelled and Non-labelled Stimulus People

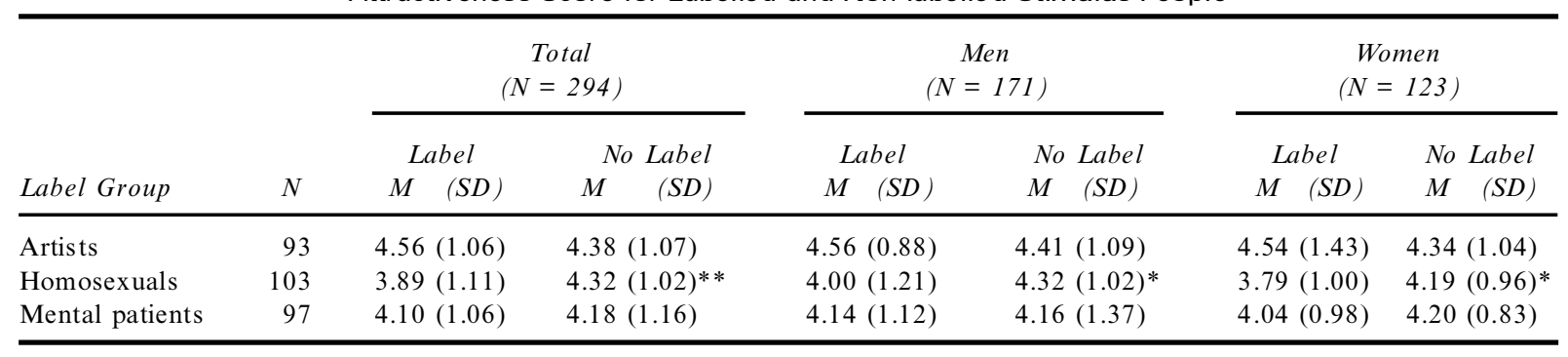

$* P<.001 ; * * P<.0001$. 
people labelled as deviants. In this type of labelling, in which labels are attached to target persons by the rater, the feature in question (such as attractiveness) is not salient but can be inferred indirectly. Webster and Driskell (1983) argued that physical attractiveness is used as a diffuse status characteristic similar to sex, race, and even age. In these terms, status is provided by the social expectation of attractive people's greater competence, and therefore serves as a useful clue of people's ability to perform tasks. We have seen this notion supported indirectly in Study 1, in which people with positive labels were considered to be more attractive than people with negative labels. Therefore it is hypothesized that when people are given the opportunity to attach labels to others, they tend to attach labels of deviancy to people they judge as less attractive. Deviants are undoubtedly considered to have lower status in any society, and since we have lesser expectations about their competence we also tend to consider them as less attractive. Study 3 employed the same set of stimulus persons used in the previous study. This set comprised of 16 target persons whose attractiveness was evaluated beforehand in a no-label condition. Subjects were told that eight of these target persons were either artists, homosexuals, or mental patients, whereas the remaining eight persons were ordinary people. Subjects were asked to select the pertinent people.

\section{Method}

Subjects and Design. The subjects were 124 undergraduates (63 females and 62 males; mean age $\pm S D=21.2 \pm 2.2$ years) enrolled at either Meikai University or a small women's college (name withheld), both in the Tokyo metropolitan area. All were native Japanese who participated at the request of their instructors. The design consisted of two between-subjects factors: group and subjects' sex, and one within-subjects factor: labelling (scores of eight persons labelled vs. the eight non-labelled persons).

\section{Testing Material.}

1. Stimuli-Sixteen portraits of Japanese male adults used in Study 2 were employed. In the present study, however, they were arranged in two clusters ("portrait sheets") each comprising eight $8 \times 6 \mathrm{~cm}$ photographs in four order varia- tions. A unique letter of identification was placed next to each portrait.

2. Questionnaire-The questionnaire contained a list of letters matching the letters on the portrait sheets. Three forms of questionnaires were prepared, each of them dealing with a separate label condition. Each condition included a statement that eight of the unidentified pictures belonged to one group of labelled people (either mental patients, homosexuals, or artists), whereas the remaining eight pictures belonged to ordinary persons (no-labelled people). Subjects were asked to mark the letters of the persons they thought belonged to the labelled group.

Procedure. Similarly to the previous study, the experiment was presented as "Research regarding the relation between face and genetic constitution". Each subject randomly received one of the three questionnaires and the portrait sheets. The subjects were provided with an explanation regarding the experiment identical to the one used in Study 2. The subjects were instructed to observe the faces carefully and to mark the eight pictures of the people whom they thought belonged to the labelled group they had been told about. In this way, each subject divided the portraits into eight labelled and eight nonlabelled targets. Upon completion, they were debriefed about the manipulation and the goals of the study.

\section{Results}

The judgement made in the no-label condition in Study 2 provided us with reliable attractiveness ratings for each of the 16 portraits, which were used again in this study. Although the raters in Study 2 and Study 3 were not the same, the large sample of students in Study 2 is assumed to provide a fair representation of students in the area of Tokyo and its periphery. Thus, we could indirectly assess the attractiveness judgement of the pictures selected in this study by matching the eight portraits each subject marked as well as the remaining portraits with their original attractiveness scores. In this way, for each subject we had one mean attractiveness score for the eight pictures he or she assigned to one of the three label conditions, and another mean attractive score for the eight unassigned (or nonlabelled) pictures, which represented "ordinary people". 
A mixed-design ANOVA with the group and subjects' sex and with repeated measures of the mean attractiveness scores for the labelled and non-labelled portraits (eight photos each) yielded a main effect of labelling, $F(1,116)=13.7$, $P<.0003$, and an interaction between labelling and label group, $F(2,116)=17.7, P<.0001$. Portraits of people labelled as homosexuals $(M=$ 4.35) and artists $(M=4.31)$ were rated as the most attractive, whereas portraits of people labelled as mental patients were rated as the least attractive $(M=4.01)$. Planned comparisons within each group yielded a main effect of labelling only for mental patients, whose mean attractiveness ratings for eight portraits was significantly lower $(M=4.01)$ than those of the non-labelled portraits $(M=4.55), F(1,41)=$ 53.9, $P<.0001$ (see Table 3 ).

In addition, we examined the correlations between the number of times each picture was selected within each label group. There was a high correlation between the choice of pictures in the artists and the homosexuals label groups, $r=.68, P<.003$ (16 items), but no correlation between the pictures selected for either the artists and the mental patients groups $(r=.12)$ or between the mental patients and the homosexuals groups $(r=-.003)$.

\section{Discussion}

The results indicate that when subjects were given the opportunity to attach labels of artist or homosexual by themselves, their choice of stimuli was not affected by attractiveness level. In contrast, when asked to attach the mental patient label, the subjects selected target people less attractive than the average. The high correlation obtained between the portraits selected in the artist and the homosexual conditions suggests that Japanese students have similar attractiveness stereotypes for faces of male artists and homosexuals, but different stereotypes for faces of male mental patients.

\section{STUDY 4}

\section{Effect of Self-generated Labelling on Attractiveness Judgement (2)}

\section{Overview}

The fourth study sought to examine whether the number of people labelled as deviant within a specific group affects their attractiveness ratings. Identical in most of its features to Study 3 , this study reexamined the effect of self-generated labelling, differing only in the number of target persons labelled. Whereas in the pervious study, subjects were asked to assign eight portraits in each label condition, in this study they were not instructed as to how many labelled persons they ought to select. It was hypothesized that the free choice of target persons would slightly overstate the labelling effect obtained in Study 3, because subjects may assign only the most or least attractive persons to each of the label groups. It was also expected that the number of portraits selected in each group in this study would correlate with the number of portraits selected in each group in Study 3 .

\section{Method}

Subjects and Design. The subjects were 90 undergraduates (52 females and 38 males, mean age $\pm S D=19.2 \pm 0.9$ years) enrolled in Meikai University. All were native Japanese who participated at the request of their instructors. The design consisted of two between-subjects factors: group and subjects' sex, and one within-subjects factor: labelling (the score of the target persons labelled vs. scores of the non-labelled persons).

\section{Testing Material.}

1. Stimuli-This used the same stimuli as in Study 3.

2. Questionnaires-This used the same questionnaires as in Study 3.

TABLE 3

Attractiveness Score for Labelled and

Non-Labelled Stimulus People (8 Selections)

\begin{tabular}{lcccc}
\hline & \multicolumn{4}{c}{ Labelled } \\
Label Group & $N$ & $M \quad(S D)$ & $M \quad(S D)$ & $F$ \\
\hline Artists & 40 & $4.31(0.21)$ & $4.33(0.21)$ & 0.1 \\
Homosexuals & 39 & $4.35(0.24)$ & $4.29(0.23)$ & 0.2 \\
Mental patients & 40 & $4.01(0.21)$ & $4.55(0.20)$ & $53.9 * *$ \\
\hline
\end{tabular}

$* P<.001 ; * * P<.0001$. 
Procedure. The procedure was the same as that in Study 3 with one difference: the subjects were told that the portraits in each condition contained one or more persons who belonged to a labelled group (each subject received one label condition). The subjects were instructed to mark those target persons, and in this way could assess the mean attractiveness score for labelled and non-labelled targets for each subject.

\section{Results}

Similar to the procedure explained in Study 3, we assessed the attractiveness judgement of the pictures selected in this study by matching the portraits each subject marked as well as the remaining portaits with their attractiveness scores from Study 2. In this way, for each subject we had one mean attractiveness score for the pictures he or she assigned to one of the three label conditions, and another mean attractiveness score for all the remaining unassigned (or non-labelled) pictures, which were represented as ordinary people.

A mixed-design analysis of variance (ANOVA) with the group and subjects' sex and with repeated measures of the mean scores for labelled and non-labelled pictures was performed. The analysis revealed main effects of labelling and group, $F(1,84)=10.0, P<.015 ; F(2,84)=$ $5.7, P<.005$, respectively, as well as an interaction between labelling and group, $F(2,84)=8.0$, $P<.0006$. Portraits of people labelled as artists $(M=4.40)$ and homosexuals $(M=4.31)$ were rated as the most attractive, whereas portraits of people labelled as mental patients were rated as the least attractive $(M=4.01)$. Planned comparisons within each group yielded main effect of labelling only for mental patients, whose mean attractiveness rating for the portraits assigned was significantly lower $(M=4.01)$ than the ratings for the remaining non-labelled portraits $(M=$ 4.44), $F(1,23)=17.5, P<.0004$. To examine the effect of the group on the number of target persons assigned to each label group, a 3 (group) $\times 2(\operatorname{sex})$ ANOVA was conducted on the number of labelled persons. The analysis did not yield any significant differences (Table 4).

As in the previous study, we examined the correlations between the number of times each picture was selected within each label group. There were positive but weak (and nonsignificant) correlations between the artists and the homosexuals, $r=.32(N=16)$, and between the artists and the mental patients $(r=.22)$, and virtually no correlation between the mental patients and the homosexuals $(r=.07)$.

In addition, we examined the correlations between the number of times each picture was selected within each label group in Study 3 and Study 4 . We found high correlation between the pictures assigned to the homosexual label in the two studies, $r=.86, P<.0001$ (16 items), between the pictures assigned to the mental patients label, $r=.69, P<.003$, and between the pictures assigned to the artists label, $r=.50, P<.05$.

\section{Discussion}

The results did not confirm the hypothesis that the free choice of target persons would slightly overstate the labelling effect obtained in Study 3 . In fact, the findings were almost identical to those obtained in Study 3. They indicated that when the subjects attached labels of artist or homosexual to target persons, their choice of stimuli was not affected by attractiveness level. In contrast, when asked to attach the mental patient label, the subjects chose less than averagely attractive people. Thus, we may conclude that the number of target persons the subjects labelled did not affect their attractiveness judgement.

The results also supported the reliability of the picture selection in Study 3; we found high correlations between the pictures assigned to each label group in Study 3 and the picture assigned

TABLE 4

Attractiveness Score for Labelled and Non-labelled Stimulus People (Free Selection)

\begin{tabular}{|c|c|c|c|c|c|}
\hline Label Group & $N$ & $\begin{array}{l}\text { Labelled } \\
M \quad(S D)\end{array}$ & $\begin{array}{c}\text { Non-labelled } \\
M \quad(S D)\end{array}$ & $\mathrm{F}$ & $\begin{array}{l}\text { No. labelled } \\
M \quad(S D)\end{array}$ \\
\hline Artists & 27 & $4.40(0.38)$ & $4.31(0.14)$ & 0.6 & $4.19(1.42)$ \\
\hline Homosexuals & 38 & $4.31(0.35)$ & $4.34(0.10)$ & 0.5 & $4.37(2.02)$ \\
\hline Mental patients & 25 & $4.01(0.38)$ & $4.44(0.13)$ & $17.5^{*}$ & $4.40(1.73)$ \\
\hline
\end{tabular}


to the same label group in Study 4. These correlations suggest that the self-generated labelling of certain faces is not arbitrary, although not necessarily valid, but based on certain schemata that are shared by a large social group.

\section{GENERAL DISCUSSION AND CONCLUSIONS}

This study focused on the extent labels determine social judgements, and more specifically on the effect of several labelling procedures on attractiveness judgements of social deviants. As a whole, findings of the four studies indicate that the labelling procedures may play an important role in affecting attractiveness judgements.

Study 1 employed abstract labelling, which resulted in great differences in the attractiveness judgements of various groups. In the next three studies, where concrete labelling was employed, deviancy had smaller effect on attractiveness. In the imposed labelling condition (Study 2), labelling a target person as a homosexual, but not as a mental patient, caused a decrease in his attractiveness evaluation as compared to judgements without any label. In the self-generated labelling condition (Studies 3 and 4), however, labelling a person as a mental patient but not as a homosexual caused a decrease in his attractiveness evaluation as compared to judgements without any label.

The difference in magnitude between abstract labelling and concrete labelling is a result of the activation of different stereotypes. In Study 1, subjects focused on the schematic label rather than on personal features and only few competing representations could disrupt their representation of the schema. In Studies 2-4, however, subjects were exposed to perceptual images of individuals rather than general images of a group to which they were supposed to belong, and several unknown competing real or perceived features of each target could interfere with their judgement.

The limited variation in attractiveness judgement obtained in Studies 2-4 suggests that in the case of physical attractiveness, at least, individuating target case information outweighs categorybased information (cf. Eagly et al., 1991). This is because attractiveness judgement appears to be affected by multitude (physical) characteristics rather than by a few basic categories. Furthermore, attractiveness judgement is essentially based on the characteristics of the stimulus person and to a much lesser extent on the characteristics or disposition of the beholder (Kowner \& Ogawa, 1995). Admittedly, the target persons used here had no relation to the labels and thus they preclude an assessment of the physical evaluation of social deviant groups in Japan. Nevertheless, it is argued that even if adequate samples of homosexuals, mental patients, or artists had been used, attractiveness evaluation would have been much less polarized than under abstract labelling.

These findings differ substantially from the findings of Farina, Fischer, Boudreau, and Bent (1996), who concluded that the abstractness of the mentally troubled individual does not appear to influence social stigmatization importantly. Farina et al. attempted to examine the effect of five different levels of abstractness (reading a transcript of an interview, listening to a recording of it, watching it on a video, hearing it live, and watching it live) on judgement of the level of sociability and achievement of a person labelled as ex-mental patient versus controls. The results indicated the existence of an unsystematic effect of abstractness on achievement, and that the subjects remembered a decreased number of aspects of the target person with increasing reality of the target person. The lack of strong effect of abstractness in the study of Farina et al. may be attributed to the fact that, even in the most abstract, and supposedly the least individuating, level, there were many personal details about the targets. In addition, the decreasing level of abstractness had little to do with the features evaluated, whereas in the present study the change in level of abstractness adds much information about the features the subjects are asked to judge.

There were also differences between the effects of imposed labelling (Study 2) and selfgenerated labelling (Studies 3-4) on attractiveness judgement, as in the former procedure one group (homosexuals) was exclusively "derogated" whereas in the latter procedure another group (mental patients) was exlusively "derogated". Several factors that underlie these two types of labelling procedures may account for the findings. The first difference is that in imposed labelling, the demand for attractiveness judgement is overt, whereas in self-generated labelling it is covert. This implies that social attitudes toward labelled targets may affect their judgement only in the overt labelling, whereas the genuine schema regarding the appearance and attractiveness of labelled targets may appear in the covert labelling. 
These differences between imposed and selfgenerated labelling suggest that the two labels, mental patients and homosexual, differ substantially. The data suggest that our subjects genuinely believed that targets labelled as mental patients are less attractive than non-patients, but they have no such underlying schema regarding the appearance of homosexuals. As for affective attitudes, the subjects appeared to have greater negative attitudes tow ard homosexuals than mental patients, or at least they were less inclined to mask these attitudes when they were aware of the task of attractiveness judgement. Thus, when the subjects conducted imposed labelling, in which they were aware of the task, their need to represent a benevolent and "liberal" facade amended the negative schema they held regarding mental patients' appearance, whereas the negative attitudes they held toward homosexuals had a detrimental effect on their judgement of appearance. In contrast, when the subjects conducted selfgenerated labelling, in which they were unaware of the task, they considered only mental patients as less attractive than non-labelled people.

The high correlations found between the portraits selected in each group in Study 3 and Study 4 suggest that the subjects held a distinct image regarding the typical face pertinent to each label. The limited number of faces used precluded a thorough examination of the typical portrait associated with each label. Nevertheless, the reliable distribution of facial selection indicates that there are one or more typical faces that laymen deem to fit a description of various deviants. The observation that faces can serve as stimuli triggering consensual stereotypical responses was earlier demonstrated by Goldstein, Chance, and Gilbert (1984). They found that certain photos were selected by the majority of raters as a "mass murderer", "armed robber", or "rapist", while others were selected as a "medical doctor", "clergyman", or "engineer". These findings bring to mind Lombroso's theory, yet there is no clear evidence regarding the link between certain physiognomy and criminality. It is all an image. These findings do have, however, great importance in the court, where judges or jurors might harbour similar preconceptions or merely associate low attractiveness with deviancy (for a review on the effect of attractiveness in court, see Bull \& Rumsey, 1988).

After examining attractiveness ratings in the present study, we ought to re-evaluate the subjects' beliefs regarding the labels used, especially their attitudes toward homosexuals and mental patients. As stereotypes of deviancy are customarily associated with lower ratings of physical attractiveness, the findings indicate that both men and women in Japan share strong negative stereotypes toward mental patients. The negative attitude tow ard homosexuals, however, appears to be more pronounced among men. The data also suggests that current notions of social desirability dictate stronger negative attitudes toward homosexuals than toward mental patients. The attitudes toward homosexuals and mental patients expressed by the Japanese male raters in the present study resemble those found in two studies conducted earlier in the USA (Simmons, 1969; Ward, 1979).

All in all, the Japanese attitudes toward deviants revealed in this study resemble the negative attitudes found earlier in other Western countries, and thus they suggest that the link between deviancy and perception of low attractiveness may have some universal roots. As such, this study provides cross-cultural support for the role of stereotypes in attractiveness judgement of social deviants, as well as advancing the universal notion of social cognition.

\section{The Labelling, Stereotyping, and Processing Pattern}

Abstract labelling obviously leads to great differences between attractiveness judgements of various groups as it activates crude categories without any individuation. When conducting concrete labelling, however, raters face a narrower range of attractiveness as compared to the imagery range. Studies 2-4 stimuluated categorybased representation (top-down processing), in which the target persons (with the exception of individuating features that would be attached directly to the specific object) were associated with the category (Brewer, 1988). Being unfamiliar with the targets and having virtually no information about them other than the labels, subjects were unable to move to a stage of personalization. However, it is suggested that increasing familiarity with a labelled target has a tendency to reduce extreme stereotypes even further, because there is a change from category-based structure to a personalized structure of information processing (bottom-up processing). This effect of familiarity is similar to Kunda and Thagard's (1996) parallelconstraints-satisfaction theory, which assumes that social stereotypes and individuating information 
constrain each others' meaning and jointly influence impressions of individuals. In a person-based representation, attractiveness judgement is the closest to a no-label condition since group targets are labelled as subordinate to the concept of each target.

The correlations found between ratings for each picture under the three labels in Studies 3 and 4 indicate that people are processing perceptual stimuli by a matching-to-sample technique. Goldstein et al. (1984) suggested that the sample is a prototypic image or a memory representation of a face, or, in our case, a subjects' schema of the prototypic face of homosexual versus non-homosexual face, mental patient versus non-mental patient, and artist versus non-artist. Indeed, the contemporary approach to stereotypes contains a seminal assumption; Stangor and Lange (1994, p. 361) maintain that "people possess abstract knowledge representations of the characteristics that they perceive to be true of the members of social groups". Moreover, Brewer and Lui's (1983, cited by Brewer, 1988) study indicates that people have and access visual representation of social categories more than corresponding verbal labels. In other words, they easily agree on the photos that match personality and behavioural attributes characterizing members of a certain social category, but find it difficult to provide a verbal label for these person types.

The differential effect of various labelling patterns calls for greater attention from social psychologists when conducting research on stereotyping, prejudice, and labelling. Researchers ought to define the mode of labelling used in their study and be aware that impression formation may vary if a different labelling pattern were to be employed.

\section{Physical Attractiveness Stereotypes of Social Deviants: Is There a "Kernel of Truth"?}

A final issue concerns the validity of attractiveness judgement of people labelled as deviants. There is no doubt that people's perceptions may often accurately reflect social reality (e.g. Higgins \& Bargh, 1987; Jussim, 1989). Further, people display a disposition to build categories around feature co-occurences, which are assumed to parallel the distribution of attributes in the real world of objects (Rosch, 1978). Yet, is this assumption valid to social cognition of deviancy? Although there is no evidence that certain physiognomic features are more common among people of a specific form of social deviancy, several studies have shown that people suffering from mental illness were rated as less attractive. Farina et al. (1977) found that female mental patients were decidedly less physically attractive than normal controls. Furthermore, among mental patients, less attractive patients had more severe diagnosis and were hospitalized for longer periods. In a second study concerning discharged mental patients of both sexes, Farina, Austad, Burns, Bugglin, and Fischer (1986) found that the more physically attractive patients stayed out of the hospital longer.

In contrast to the plausible link between mental disorder and low attractiveness, homosexual men may actually be more attractive than heterosexuals. Gays' concern for physical appearance, Symons (1979, p. 204) argued, is "not because they are as a group, effeminate, but simply because they face the same problem that heterosexual women face: they wish to be sexually attractive to males, and males assess sexual attractiveness primarily on the basis of physical appearance".

Gangestad (1993) contended that human sexual selection tends to favour individuals who epitomize their gender characteristics. This means that the presence of distinctive visible gender characteristics, and the lack of distinctive characteristics of the opposite gender, are important determinants of physical attractiveness, because they indicate a maximization of the reproductive prospects. Kite and Deaux (1987) pointed out that homosexual men are commonly perceived as being "feminine" and possessing a "high-pitched voice", while lesbians are perceived as being "masculine" and having "short hair". Although rapidly changing, the common images of homosexuals, as removed from their gender archetype, may explain their low attractiveness in the eyes of certain heterosexuals. The question is, indeed, whether gays are more effeminate and thus more recognizable?

Although there is not enough data to answer this question, there is much heuristic value in Becker's (1963, p. 9) definition of deviant people as those "to whom that label has successfully been applied"'. Similarly, Scheff (1966) argued that, without labelling, most residual rule-breaking committed by the mentally ill will be ignored or denied and pass away as a matter of transitory significance. Thus, it seems reasonable to assume that homosexuals' beauty is not derogated unless recognized as such. 
The evidence for the existence of an occasional kernal of truth regarding the attractiveness judgement of people labelled as deviants suggests that sometimes people's perceptions may accurately reflect social reality. Nevertheless, the general conclusion of this study supports the notion that social perception often creates, rather than reflects, social reality.

Manuscript first received April 1997 Revised manuscript accepted August 1997

\section{REFERENCES}

Alley, T.R. (1988). Physiognomy and social perception. In T.R. Alley (Ed.), Social and applied aspects of perceiving faces (pp. 167-189). Hillsdale, NJ: Law rence Erlbaum Associates Inc.

Barocas, R., \& Vance, F.L. (1974). Physical appearance and personal adjustment counselling. Journal of Counselling Psychology, 21, 96-100.

Becker, H.S. (1963). Outsiders: Studies in the sociology of deviance. New York: Free Press.

Berry, D.S., \& McArthur, L.Z. (1986). Perceiving character in faces: The impact of age-related craniofacial changes on social perception. Psychological Bulletin, 100, 3-18.

Berscheid, E., \& Walster, E.H. (1974). Physical attractiveness. In L. Berkowitz (Ed.), Advances in experimental social psychology, Vol. 7 (pp. 156213). New York: Academic Press.

Brandt, A. (1980). Face reading: The persistence of physiognomy. Psychology Today, 14, 90-96.

Brewer, M.B. (1988). A dual process model of impression formation. In T.K. Srull \& R.S. Wyer (Eds.), Advances in social cognition, Vol. 1: A dual process model of impression formation (pp. 1-36). Hillsdale, NJ: Law rence Erlbaum Associates Inc.

Bull, R., \& Rumsey, N. (1988). The social psychology of facial appearance. New York: Springer Verlag.

Clinard, M.B. (1968). Sociology of deviant behavior. New York: Holt, Rinehart, \& Winston.

Conrad, P., \& Schneider, J.W. (1980). Deviance and medicalization. St. Louis, MO: C.V. Mosby.

Deaux, K., \& Lewis, L. (1984). The structure of gender stereotypes: Interrelationships among components and gender labels. Journal of Personality and Social Psychology, 46, 991-1004.

Dinitz, S., Dynes, R.R., \& Clark, A.C. (1969). Deviance: Studies in the process of stigmatization and societal reaction. New York: Oxford University Press.

Dion, K., Berscheid, E., \& Walster, E. (1972). What is beautiful is good. Journal of Personality and Social Psychology, 24, 285-290.

Dovidio, J.F., Evans, N.E., \& Tyler, R.B. (1986). Racial stereotypes: The contents of their cognitive representations. Journal of Experimental Social Psychology, 22, 22-37.

Eagly, A.H., Ashmore, R.D., Makhijani, M.G., \& Longo, L.C. (1991). What is beautiful is good, but .... A meta-analytic review of research on the physical attractiveness stereotype. Psychology Bulletin, 110, 109-128.

Farina, A., Austad, C., Burns, G.L., Bugglin, C., \& Fischer, E.H. (1986). The role of physical attractiveness in the readjustment of discharged psychiatric patients. Journal of Abnormal Psychology, 95, 139-143.

Farina, A., Fischer, E.H., Boudreau, L.A., \& Bent, W.E. (1996). Mode of target presentation in measuring the stigma of mental disorder. Journal of Applied Social Psychology, 26, 2147-2156.

Farina, A., Fischer, E.H., Sherman, S., Smith, W.T., Groh, T., \& Mermin, P. (1977). Physical attractiveness and mental illness. Journal of Abnormal Psychology, 86, 510-517.

Feingold, A., (1992). Good-looking people are not what we think. Psychological Bulletin, 111, 304341.

Fiske, S.T., \& Neuberg, S.L. (1990). A continuum of impression formation, from category-based to individuating processes: Influences of information and motivation on attention and interpretation. In M.P. Zanna (Ed.), Advances in experimental social psychology, Vol. 23 (pp. 1-74). New York: Academic Press.

Gangestad, S.W. (1993). Sexual selection and physical attractiveness: Implications for mating dynamics. Human Nature, 4, 205-239.

Goldberg, P.A., Gottesdiener, M., \& Abramson, P.R. (1975). Another put-down on women? Perceived attractiveness as a function of support to the feminist movement. Journal of Personality and Social Psychology, 31, 113-115.

Goldstein, A., Chance, J.E., \& Gilbert, B. (1984). Facial stereotypes of good guys and bad guys: A replication and extension. Bulletin of the Psychosomatic Society, 22, 549-552.

Graham, J. (1993). Contexts of physiognomic description: Ut pictura poesis. In E. Shookman (Ed.), The faces of physiognomy: Interdisciplinary approaches to Johann Caspar Lavater (pp. 139-144). Columbia, SC: Camden House.

Gurwitz, S.B., \& Marcus, M. (1978). Effects of anticipated interaction, sex, and homosexual stereotypes on first impressions. Journal of Applied Social Psychology, 8, 47-56.

Hannson, R.O., \& Duffield, B.J. (1976). Physical attractiveness and the attribution of epilepsy. Journal of Social Psychology, 99, 233-240.

Hatfield, E., \& Sprecher, S. (1986). Mirror, mirror: The importance of looks in everyday life. Albany, NY: State University of New York Press.

Hayashida, C.T. (1976). Identity, race and the blood ideology of Japan. PhD Dissertation, University of Washington.

Higgins, E.T., \& Bargh, J.A. (1987). Social cognition and social perception. Annual Review of Psychology, 38, 369-425.

Innala, S.M., \& Ernulf, K.E. (1994). When gay is pretty: Physical attractiveness and low homophobia. Psychological Reports, 74, 827-831.

Jacobson, E.H., \& Koch, W. (1978). Attributed reasons for support of the feminist movement as a function of attractiveness. Sex Roles, 4, 169-174. 
Johnson, R.W ., Doiron, D., Brooks, G.P., \& Dickinson, J. (1978). Perceived attractiveness as a function of support for the feminist movement: Not necessarily a put-down of women. Canadian Journal of Behavioral Science, 10, 214-221.

Johnson, R.W., Holborn, W.W., \& Turcotte, S. (1979). Perceived attractiveness as a function of active versus passive support for the feminist movement. Personality and Social Psychology Bulletin, 5, 227-230.

Jones, W.H., Hannson, R.O., \& Phillips, A.L. (1978). Physical attractiveness and judgements of psychopathology. Journal of Social Psychology, 105, 79-84.

Jussim, L. (1989). Teacher expectations: Self-fulfilling prophecies, perceptual biases, and accuracy. Journal of Personality and Social Psychology, 57, 469-480.

Jussim, L. (1991). Social perception and social reality: A reflection-construction model. Psychological Review, 98, 54-73.

Jussim, L., Nelson, T.E., Manis, M., \& Soffin, S. (1995). Prejudice, stereotypes, and labelling effects: Sources of bias in person perception. Journal of Personality and Social Psychology, 68, 228-246.

Kite, M.S., \& Deaux, K. (1987). Gender belief systems: Homosexuality and the implicit inversion theory. Psychology of Women Quarterly, 11, 8396.

Klatzky, R.L. (1984). Visual memory: Definitions and functions. In R. Wyer \& T. Srull (Eds.), Handbook of social cognition, Vol. 2 (pp. 233-270). Hillsdale, NJ: Lawrence Erlbaum Associates Inc.

Klatzky, R., Martin, G.L., \& Kane, R.A. (1982). Influence of social-category activation on processing of visual information. Social Cognition, 1, 95-109.

Kowner, R. (1996). Effect of group status on physical attractiveness preferences-From the Japanese case to a general cognitive perspective. Genetic, Social, and General Psychology Monographs, $122,215-248$.

Kowner, R., \& Ogawa, T. (1995). The role of raters' sex, personality, and appearance in judgements of facial beauty. Perceptual and Motor Skills, 81, 339349.

Kunda, Z., \& Thagard, P. (1996). Forming impressions from stereotypes, traits, and behaviors: A parallel-constraints-satisfaction theory. Psychological Review, 103, 284-308.

Lombroso, C. (1887). L'homme criminel. Paris: F. Alcan.

Markus, H.R., \& Kitayama, S. (1991). Culture and the self: Implication for cognition, emotion, and motivation. Psychological Review, 98, 224-253.

McArthur, L.Z. (1982). Judging a book by its cover: A cognitive analysis of the relationship between physical appearance and stereotyping. In A. Hastorf
\& A. Isen (Eds.), Foundations of interpersonal attraction (pp. 149-211). New York: Academic Press.

Munakata, T. (1989). The socio-cultural significance of the diagnostic label "neurasthenia" in Japan's mental health system. Culture, Medicine and Psychiatry, 13, 203-213.

Plato (1963). The collected dialogues. Edited by Edith Hamilton and Hunting Cairns (Bollingen Series editors). Princeton, NJ: Princeton University Press.

Rivers, C. (1994). Face value: Physiognomical thought and the legible body in Marivaux, Lavater, Balzac, Gautier, and Zola. Madison, WI: The University of Wisconsin Press.

Rosch, E. (1978). Principles of categorization. In E. Rosch \& B.B. Lloyd (Eds.), Cognition and categorization. Hillsdale, NJ: Law rence Erlbaum Associates Inc.

Scheff, T. (1966). Being mentally ill: A sociological theory. Chicago, IL: Aldine.

Shepherd, J.W., Ellis, H.D., McMurran, M., \& Davies, G.M. (1978). Effect of character attribution attractiveness on photofit construction of a face. European Journal of Social Psychology, 8, 263-268.

Simmons, J.L. (1969). Deviants. Berkeley, CA: Glendessary Press.

Stangor, C., \& Lange, J.E. (1994). Mental representations of social groups: Advances in understanding stereotypes and stereotyping. In M.P. Zanna (Ed.), Advances in experimental social psychology, Vol. 26 (pp. 357-416). San Diego, CA: Academic Press.

Steffensmeier, D., \& Steffensmeier, R. (1974). Sex difference in reactions to homosexuals: Research continuities and further developments. The Journal of Sex Research, 10, 52-67.

Symons, D. (1979). The evolution of human sexuality. New York: Oxford University Press.

Unger, R.K., Hilderbrand, M., \& Madar, T. (1982). Physical attractiveness and assumptions about social deviance: Some sex by sex comparisons. Personality and Social Psychology Bulletin, 8 , 293-301.

Ward, R. (1979). Typifications of homosexuals. Sociological Quarterly, 20, 411-423.

Watanabe, T., \& Iwata, J. (1989). The love of the Samurai: Thousand years of Japanese homosexuality (originally published in France, 1987, translated by D.R. Roberts). London: GMP Publishers.

Webster, M., \& Driskell, J.E. (1983). Beauty as status. American Journal of Sociology, 89, 140-165.

Weinberg, G. (1972). Society and the healthy homosexual. Garden City, NY: Anchor Books.

Weisz, J., Rothbaum, F., \& Blackburn, T. (1984). Standing out and standing in: The psychology of control in America and Japan. American Psychologist, 39, 955-969.

Wittgenstein, L. (1958). Philosophical investigations. New York: Macmillan. 